\title{
Franc Schuerewegen, Introduction à la méthode postextuelle. L'exemple proustien
}

\section{Geneviève Henrot Sostero}

\section{(2) OpenEdition \\ 1 Journals}

\section{Edizione digitale}

URL: http://journals.openedition.org/studifrancesi/2264

DOI: 10.4000/studifrancesi.2264

ISSN: 2421-5856

Editore

Rosenberg \& Sellier

\section{Edizione cartacea}

Data di pubblicazione: 1 aprile 2014

Paginazione: 181

ISSN: 0039-2944

\section{Notizia bibliografica digitale}

Geneviève Henrot Sostero, «Franc Schuerewegen, Introduction à la méthode postextuelle. L'exemple proustien », Studi Francesi [Online], 172 (LVIII | I) | 2014, online dal 01 avril 2014, consultato il 18 septembre 2020. URL : http://journals.openedition.org/studifrancesi/2264 ; DOI : https://doi.org/ 10.4000/studifrancesi.2264

Questo documento è stato generato automaticamente il 18 settembre 2020.

\section{(c)}

Studi Francesi è distribuita con Licenza Creative Commons Attribuzione - Non commerciale - Non opere derivate 4.0 Internazionale. 


\title{
Franc Schuerewegen, Introduction à la méthode postextuelle. L'exemple proustien
}

\author{
Geneviève Henrot Sostero
}

\section{NOTIZIA}

FRANC SCHUEREWEGEN, Introduction à la méthode postextuelle. L'exemple proustien, Paris, Classiques Garnier, 2012 («Théorie de la littérature», 4), pp. 245.

1 Come leggere la letteratura, da critico? Ogni epoca convoglia con sé credo e usanze. Dopo la filologia, lo strutturalismo e il post-strutturalismo, ecco un altro "post-", che getta sul testo una manciata di sospetti: il testo vero, l'A. lo colloca, non a monte della lettura (un testo che già esiste nella propria evidenza e serve da punto di partenza), bensì a valle, ovvero un oggetto personale ancora da architettare («Introduction. Questions de méthode», pp. 11-30 e «Nouvelles questions de méthode», pp. 31-45). Sulla scia delle teorie tedesche della lettura, ma anche del concetto di testo-fantasma secondo Michel Charles, l'A. interpella la propria memoria di lettore come una voce latente e fluttuante. L'écoute flottante dello psicanalisi diventa la lecture flottante del critico, pronta a cogliere al volo somiglianze e richiami, accostamenti e paragoni, in nome del sacrosanto "diritto" ad elaborare di sana pianta il senso ("un" senso tra tanti altri) del testo "per me lettore": «On ne lit pas un texte, on le construit», si afferma nell'introduzione. Il metodo rivendica la piena autonomia del lettore rispetto ad un presunto e sempre misterioso "voler dire" dello scrittore, sbandiera il diritto ad una lettura sincopata, intermittente, serpeggiante, che si sofferma anche su episodi molto brevi, su motivi, su frammenti: ostriche e uccelli, campane e madelaines («Comment écrire soi-même des postextes», pp. 47-61), manifesti e barattoli («Analyse du beau et du pot», pp. 181-202). Pertanto la lettura "di palo in frasca" si fa potenzialmente reticolare, in quanto veicola verso il brano in esame l'ombra di altri testi: Michelet e Casanova (in «Huîtres», pp. 63-78), Balzac, Baudelaire e Flaubert (in «Oiseaux 
domestiques de basse-cour, et autres bêtes», pp. 79-93), Tolstoï (in «La Patineuse de Balbec», pp. 95-111), Olivier Rolin (in «À quel âge faut-il lire Proust?», pp. 113-128).

2 Anche all'interno della fucina narrativa, la memoria viene svincolata da presunte fonti individuali (il focus del punto di vista): di chi sono veramente i ricordi narrati, se il narratore si lamenta di aver dimenticato tutto, mentre Charlus compare a fagiolo per ricordargli i fatti più salienti del suo romanzo («Pourquoi Charlus est le véritable auteur de la Recherche du temps perdu?», pp. 129-142)? Con (auto)ironia e palese divertimento, il critico fa girare la giostra degli intertesti (che non si chiamano più così), interrogando in modo inedito i rapporti di Proust con Nietzsche («Tentative de reconstruction d'un Proust "nietzschéen"», pp. 143-162), o con il dadaismo ("Quelques progrès dans l'étude du dadaïsme proustien», pp. 163-180), o ancora con Chateaubriand ma filtrato a valle da Roland Barthes («La Préparation du roman», pp. 201-220). Brillanti passeggiate nei boschi letterari, che ricordano un po', per il tono enlevé, l'audacia e l'importanza dell'io critico, Gérard Genette, oppure Umberto Eco. 